depends largely upon the duration of a combination of favourable conditions in the endemic areas and in the southern portions of the State. A detailed study of the ecology of the species is in progress.

Waite Research Institute, JAMES DAvidson.

University of Adelaide. June 15.

1 J. C. Faure, Bull. Entom. Res., 22, 393 ; 1932.

2 J. Davidson, Aust. J. Exp. Biol. and Med. Sci., 11, 59; 1933. Trans. Roy. Soc. South Australia, 58, 33; 1934.

J. A. Prescott, Trans. Roy. Soc. South Australia, 58, 48; 1934.

\section{Wood Hemicelluloses}

Since the isolation of 'starch' from wood' another product has been obtained from the cell walls of oak sapwood which, instead of giving the usual blue colour with iodine, gives a royal purple colour reverting to blue on standing. This latter substance is more closely allied to hemicellulose $A^{2}$ than the starch of the cell contents since it appears to be made up of :

Uronic and aldobionic anhydride residues

(14 per cent approx.)

in addition to-.

Anhydro-xylose $\quad \ldots \quad$. $\quad$ (10 per cent approx.) and

Anhydro-glucose residues .. (75 per cent approx.)

Attempts are now being made to prepare starch from oak leaves in quantities sufficient for analysis. A small sample already obtained has yielded on hydrolysis with 12 per cent hydrochloric acid an amount of carbon dioxide corresponding to $24 \cdot 4$ per cent of uronic anhydride. These results appear to permit of the formulation of the hypothesis that certain of the hemicelluloses of oak wood are derived from starch in a series of steps involving the oxidation of primary alcoholic groups and the subsequent formation of anhydro-xylose residues by decarboxylation. If the hypothesis is correct, the term 'hemicellulose' can no longer be applied to the acid polysaccharides in question, and the alternative general term 'amylo-uronides' is therefore suggested. If the furfuraldehyde-yielding complexes associated with the cellulose of wood are derived therefrom by a similar series of reactions, the term 'hemicellulose' might still be reserved for them.

W. G. Campbell.

Department of Scientific and Industrial Research,

Forest Products Research Laboratory,

Princes Risborough, Aylesbury, Bucks. July 6

${ }^{1}$ Campbell, Biochem. J., 29, 1068; 1935.

O'Dwyer, Biochem J., 23, 2116: 1934.

\section{Amorphous Antimony}

IN a previous letter ${ }^{1}$, I showed that a thin layer of antimony produced by distillation in a high vacuum is amorphous. This conclusion was drawn from the fact that the electron diffraction pattern consisted of broad bands always showing exactly the same appearance (width, intensity, etc.); this could scarcely be understood if the state were only colloidal. The following researches corroborate and extend this view :

When such an amorphous layer is heated to $120^{\circ}$ $150^{\circ} \mathrm{C}$. (the thinner layers requiring the higher temperatures), the diffraction pattern changes into the ordinary powder diagram of antimony, consisting of a large number of sharp rings. If the original layer was very thin, the rings after heating remain more or less broad as a consequence of the small size of the crystallites; the difference from the original amorphous pattern is, however, unmistakable even in this case. In all cases the crystallites produced by heating are oriented at random, differing in this respect from those formed by spontaneous crystallisation at room temperature, described previously.

These results throw a new light on the so-called 'explosive' state of antimony, discovered by Gore almost a century ago. As is well known, this state is obtained by electrodeposition; in this case there is no upper limit to the thickness of the deposit obtainable. The diffraction patterns of such layers ${ }^{2}$ proved to be identical with those of amorphous antimony described above. This shows that Gore's explosive antimony is essentially identical with our pure amorphous antimony. Explosive antimony is known, however, to include some 10 per cent of the salt electrolysed; this may be present as thin films (probably monomolecular) surrounding small quantities of pure amorphous metal, thereby inhibiting their crystallisation.

From this picture, it may be expected, for example, that the electric resistance of explosive antimony will not be determined by the metallic parts but mainly by the salt films ${ }^{3}$. Experimentally, I have found values for the resistivity about 100 times that of ordinary antimony, and other observers ${ }^{4}$ even give a factor 1000 . These high values, as well as their irreproducibility, are arguments in favour of the view put forward above. Other properties, how ever, might be less sensitive to the presence and quantity of inclusions, should then be the same as for pure amorphou here consider the $7 v$. As such we shall ":sation and the diamagnetic suscep

It is well know its name from th nv derives less explosively may now say, This 'explos:"

heating to

lisation $\mathrm{f}$

Cohen ar

This is $c$

of crysta.

point (24 ca

susceptibility

it increases mar.

antimony is brous

ment with the chan

at the melting point. 'I

suggest that the explosive (a

is the supercooled liquid stc.

The experiments were madt

Mr. P. Teunissen in the laborator,

The full paper is to appear in Phys.

Natuurkundig Laboratorium

der Rijks-Universiteit, Groningen.

July 22 .

1 NATURE, 131, 760; 1933.

I took photographs with copper $\boldsymbol{K}$-radiation; see also H. Kersten, Physics, 2, 276; 1932 .

3 Included impuritles may exert an analogous effect in sputtered layers, described by $H$. Zahn and J. Kramer, $Z$. Phys., 86, 413; 1933 H. v. Steinwehr and A. Schulze, Z. Phys., 63, 815 ; 1930.

- G. Tammann und W. Muliler, $Z$. anorg. u. allg. Chem, 221,$109 ; 1934$. 